\title{
Research on Institutional Engineering Governance Of Basic Medical Security Frauds
}

\author{
Yan Jin $^{1 *}$, Shaorong Sun ${ }^{2}$ and Oleksandra Koshevarova ${ }^{3}$ \\ 1, 2, 3 University of Shanghai for Science and Technology
}

\begin{abstract}
The basic medical security system is an important part of the social security system. In recent years, reports on the fraud of basic medical security are often seen in the public media, and have attracted the attention of the academic circle. However, the research and analysis of basic medical insurance fraud is often one-sided or superficial. In order to effectively control health care fraud, insurance fraud behavior in this paper, for the first time the application of system engineering of Sun diagram to basic health care insurance fraud behavior, from behavior management system design theory of system engineering, using the doctor-patient collusion insurance fraud behavior punishment, for the reason of basic health care insurance fraud behavior person and system defect analysis, show the inhibition of contribution to the system of medical insurance fraud behavior, and finally, combining the experience in this field in our country, puts forward the corresponding control measures. This paper puts forward the following Suggestions: 1. A standardized legal punishment system should be formed to deal with insurance fraud in basic medical security; 2 . Completely cut off the relationship between the amount of drugs and medical equipment sold by hospitals and doctors and their income in terms of system design; 3. Further clarify the coverage, fields and cost standards of basic medical insurance; 4. Improve the informatization degree of each link and process of basic medical security; 5. Strengthen the popularization and publicity of the correct use of basic medical security for the public.
\end{abstract}

Key words: basic medical security; fraudulent behaviour; collusion; institutional engineering; Sun diagram 


\section{$9^{\text {th }}$ INTERNATIONAL CONFERENCE ON}

MANAGEMENT , ECONOMICS AND HUMANITIES

\section{Introduction}

Medical insurance fund is the "life-saving money" of the common people and an important way to solve the problem of "difficult and expensive medical treatment" for the common people. But in recent years, medical insurance fraud emerged one after another, with various means. According to the audit results of medical insurance fund released by the national audit office in 2017, in 2015 and the first half of 2016, due to insufficient connection between systems, 3.05 million people repeatedly participated in basic medical insurance, resulting in 1.457 billion yuan of additional financial subsidies. 109 enterprise medical insurance funds are still closed, involving 7.7676 million employees, of which 23 enterprises are in arrears in paying medical insurance premiums, paying settlement payments to designated institutions and paying medical expenses to employees due to difficulties in production and operation. Some designated institutions and individuals defrauded to obtain medical insurance funds. It is suspected that 923 designated medical institutions and designated retail pharmacies defrauded the medical insurance fund of 207 million yuan as the unit's income accounting by means of false medical treatment and dissolving hospitalization. Also have a few natural persons to be suspected of through the means such as false different ground bill diddle fund of medical treatment insurance 100711 thousand yuan. It is suspected that 923 designated medical institutions and designated retail pharmacies defrauded 207 million yuan of medical insurance fund as the unit's income accounting by means of false medical treatment, decomposition and hospitalization. Also have a few natural persons to be suspected of through the means such as false different ground bill diddle fund of medical treatment insurance 100711 thousand yuan. Some medical institutions and agencies have raised or charged prices in violation of regulations. 474 medical institutions illegally raised prices to sell drugs and consumables by 537 million yuan. The 1,330 medical institutions adopted self-supporting projects and repeated charges, and illegally collected 599 million yuan in fees for treatment projects. Sixtyfour medical insurance agencies illegally collected 105 million yuan in network maintenance fees. On November 14, CCTV "focus interview" exposed two cases of medical insurance fraud in shenyang, attracting attention and attention from all walks of life. Ma weishu ${ }^{[1]}$ summed up three ways to cheat insurance: one is the medical institutions alone, one is the ginseng to protect personnel alone, there is a medical institutions and ginseng to protect personnel "collusion", especially in the design of "collusion" cheat insurance amount is the most, the biggest harm to the health insurance fund. Liu zhiyong ${ }^{[2]}$ analyzed that medical insurance fraud mainly includes five methods, namely, illegal treatment, forged prescription or bill, hospitalization or diagnosis and treatment under a false name, application or misappropriation of funds under a false name, and medical insurance card in drugstores and pharmacies becoming shopping card. Li yazi ${ }^{[3]}$ collected the cases of new rural cooperative medical insurance fraud in a province from 2007 to 2014, and found that the identification of fake bills mainly has the following methods: anastomosis, Actual ticket comparison, telephone and network verification, Field check. Huang guan ${ }^{[4]}$ found through a comparative study between China and the United States that most of the frauds of basic medical security in the United States were committed by the medical service providers, while in China, 


\section{$9^{\text {th }}$ INTERNATIONAL CONFERENCE ON MANAGEMENT , ECONOMICS AND HUMANITIES}

there were serious collusion between the medical service providers and the beneficiaries, as well as the frauds of the medical service beneficiaries. Lou yu ${ }^{[5]}$ believes that agencies can try to introduce punitive damages into medical service agreements. Xiong maoyou ${ }^{[6]}$ believes that the massive hospital insurance fraud is not a problem of inadequate government supervision, but a problem of the system. The total prepayment method of medical insurance throughout the country is to make the insured's actual medical insurance level greatly shrink in order to maintain the balance of medical insurance fund and implement total control.

\section{System governance of doctors and patients conspiring to defraud insurance}

Medical institutions and insured personnel make use of the loopholes in the medical security system to collude with each other, complete the process of the medical insurance system in the form, put on the appearance of legal compliance for their own insurance fraud, and seek illegitimate interests. The collusion of doctors and patients to cheat insurance is of high concealment, difficult to investigate and deal with, and the cost of supervision is relatively high. From the aspect of law enforcement, there are not many cases that are really dealt with in a timely and serious manner, and the cost of illegal insurance fraud is still relatively low. How to effectively manage the medical and patient collusion insurance fraud is a hot issue that needs to be solved at present. This paper studies the governance of medical and patient collusion insurance fraud from the perspective of system.

\section{1 examples of punishment system for colluding with doctors and patients to defraud insurance}

It is assumed that there is a certain number of doctors and patients colluding to cheat insurance in the social network. As the heterogeneous participant in the social network, the insured has certain adaptive learning ability, and the behavior set of the insured is ternary. Among them, b1 refers to that the insured turns a blind eye to the collusion between doctors and patients around the insurance, b2 refers to that the insured chooses to collude with medical institutions to cheat the insurance, and $\mathrm{b} 3$ refers to that the insured reports the collusion between doctors and patients to cheat the insurance. In the punishment system that manages a doctor and patient to conspire to cheat protect behavior, the ideal state of system design is to try to make ginseng protect a person to choose to inform against illegal behavior, it is to do not collude with medical establishment and its staff next, avoid conspire behavior finally.

When collusive behavior is better than turning a blind eye in utility, the parameter characteristics of its system are $r 2+c 2>r 1+c 1$. Think of $r 2$ as being made up of "normal returns plus nefarious gains." $\mathrm{r} 1$ is the normal return. $\mathrm{c} 2$ and $\mathrm{c} 1$ are generally not very different. Therefore, $\mathrm{r} 2+\mathrm{c} 2>\mathrm{r} 1+\mathrm{c} 1$ is always true when there is no suppressor for collusion behavior in the system (i.e., no observer p2 and punishment s2). As rational individuals, they choose collusion behavior b2. According to institutional engineering, the Sun diagram is shown in figure $1^{[7]}$. 


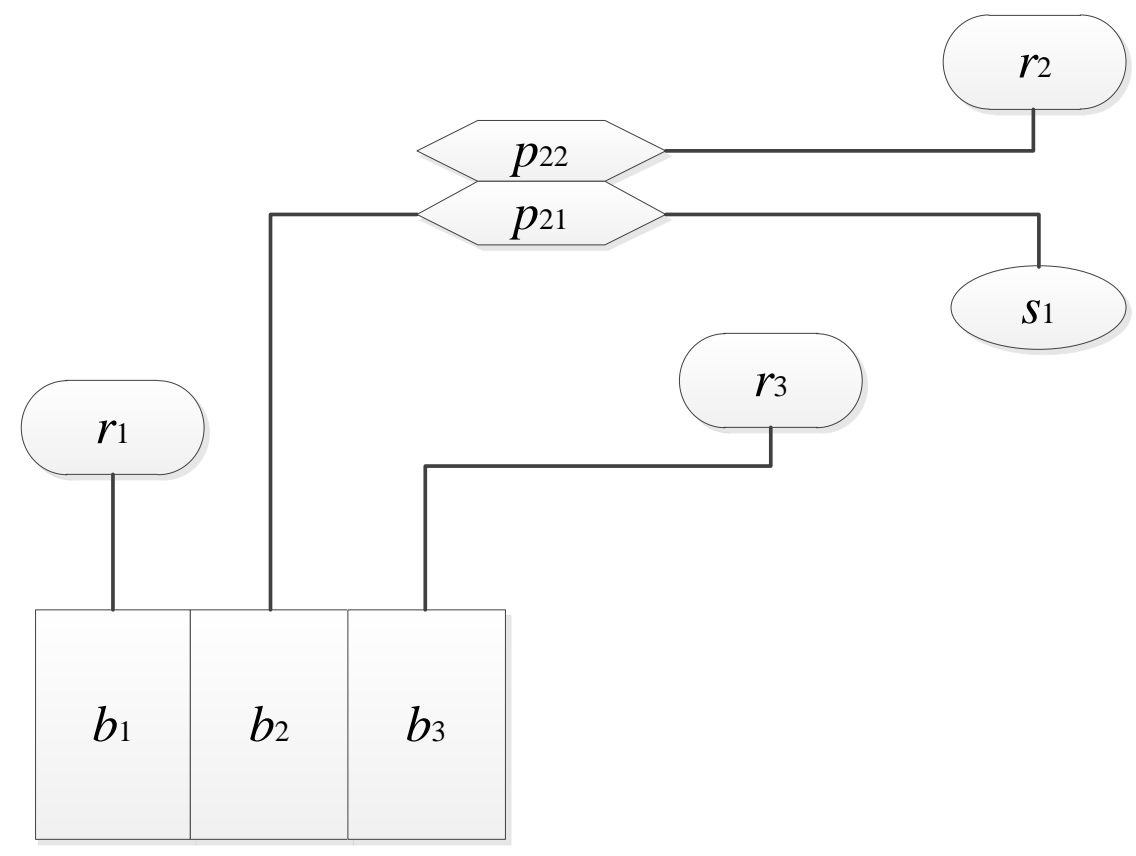

Figure 1 Sun's diagram of punishment system for doctors and patients' conspiring to cheat insurance ${ }^{[7]}$

Table 1 Parameter list of punishment system for doctor-patient collusion in insurance fraud ${ }^{[7]}$

\begin{tabular}{|l|l|l|l|l|l|}
\hline content & variables & return & probability & cost & utility \\
\hline turn a blind eye & $\mathrm{b} 1$ & $\mathrm{r} 1$ & 1 & $\mathrm{c} 1$ & $\mathrm{u} 1=\mathrm{r} 1-\mathrm{c} 1$ \\
\hline conspiracy & $\mathrm{b} 2$ & $\mathrm{r} 1$ & $\mathrm{p} 22$ & $\mathrm{c} 2$ & $\mathrm{u} 2=\mathrm{r} 2 \mathrm{p} 22+\mathrm{r} 2 \mathrm{p} 21-\mathrm{c} 2=(1-\mathrm{p} 21) \mathrm{r} 2+\mathrm{p} 21 \mathrm{~s} 2-\mathrm{c} 2$ \\
\hline & & $\mathrm{s} 2$ & $\mathrm{p} 21$ & & \\
\hline report & $\mathrm{b} 3$ & $\mathrm{r} 3$ & 1 & $\mathrm{c} 3$ & $\mathrm{u} 3=\mathrm{r} 3-\mathrm{c} 3$ \\
\hline
\end{tabular}

According to Sun's diagram 1 and parameter table $1^{[7]}$, the boundary conditions for the effective system are as follows:

When u1>u2, that's $r_{1}-c_{1}>\left(1-p_{21}\right) r_{2}+p_{21} s_{2}-c_{2}$,

instead of colluding with doctors and patients, enrollees will choose to ignore the wrongdoing. By arranging the above formula, we can get ${ }^{[7]}$

$$
\mathrm{p}_{21}>\frac{\left(\mathrm{r}_{2}-\mathrm{r}_{1}\right)-\left(\mathrm{c}_{2}-\mathrm{c}_{1}\right)}{\mathrm{r}_{2}-\mathrm{s}_{2}}
$$




\title{
$9^{\text {th }}$ INTERNATIONAL CONFERENCE ON MANAGEMENT , ECONOMICS AND HUMANITIES
}

\author{
26-28 July, 2019 \\ London, United Kingdom
}

When the performance of the observer meets the above requirements, the insured will be more inclined to choose to turn a blind eye between turning a blind eye and colluding.

When the difference between behavioral cost $\mathrm{c} 1$ and $\mathrm{c} 2$ is not significant, the above equation can be summarized as ${ }^{[7]}$

$$
\mathrm{p}_{21}>\frac{\mathrm{r}_{2}-\mathrm{r}_{1}}{\mathrm{r}_{2}-\mathrm{s}_{2}}
$$

It can be seen from the above equation that when the value of punishment s2 is larger (more positive), the return of collusion behavior is larger, and the value of $\mathrm{s} 2$ is smaller (more negative), the return of collusion behavior is smaller. However, when the observation intensity p21 is very small, the insured will be more willing to choose collusion behavior. It can be seen that increasing the punishment for collusion behavior s2 and the observer probability p21 can avoid the insured's choice of collusion behavior to some extent. There are many ways to promote s2 and p21. For example, Health Security Service Group co. ltd. assisted the medical insurance department to implement a comprehensive and multi-angle "combination" of medical insurance cost control through innovative products and services such as the whole process function audit of medical insurance, third-party payment review, DRGs fund settlement, and comprehensive medical insurance management service. At present, guoxing health insurance expense control business has covered more than 150 medical insurance pooling areas in 24 provinces (accounting for $38.25 \%$ of the total nationwide), serving 270 million insured people, covering more than 500 billion medical insurance funds, involving 40,880 designated medical institutions of various levels and types and 65,781 designated pharmacies. As of July 2017, a total of 55.38 billion yuan of illegal fees had been examined by the intelligent medical insurance examination system, and 12.9 billion yuan of non-payment had been actually made by the medical insurance departments, saving huge losses for the medical insurance fund

When $\mathrm{u} 3>\mathrm{u} 1>\mathrm{u} 2$, that's $\mathrm{r}_{3}-\mathrm{c}_{3}>\mathrm{r}_{1}-\mathrm{c}_{1}>\left(1-\mathrm{p}_{21}\right) \mathrm{r}_{2}+\mathrm{p}_{21} \mathrm{~s}_{2}-\mathrm{c}_{2}$,

instead of turning a blind eye and participating in the collusion, enrollees are more likely to report the collusion. This is the effective condition that manages doctor - patient to conspire to cheat protect behavior.

According to the $\mathrm{u}_{3}=\mathrm{r}_{3}-\mathrm{c}_{3}$, and behavioral cost $\mathrm{c} 3$ differs little from $\mathrm{c} 1$ and $\mathrm{c} 2$, so you can raise $\mathrm{u} 3$ by raising $\mathrm{r} 3$. There are many ways to promote $\mathrm{r} 3$, such as a whistleblower reward system. National health insurance bureau released on December 15, 2018 report "the fraud diddle medical insurance fund conduct rewards interim measures", has been clear about the fixed-point medical institutions and their staff, designated retail pharmacies and health care workers, ginseng protect personnel, orgnaization of agency of staff such as fraud, insurance fraud behavior as a whole the area medical security department according to verify fraud in proportion, the amount of insurance 


\section{$9^{\text {th }}$ INTERNATIONAL CONFERENCE ON MANAGEMENT , ECONOMICS AND HUMANITIES}

fraud for eligible person reward, maximum amount does not exceed 100000 yuan, aims to reward incentive policy to encourage people to report the enthusiasm.

On November 16, 2018, the ministry of human resources and social security issued the interim measures for the management of "blacklist" of serious breach of trust in the field of social insurance (draft for soliciting opinions), which intends to put the units and individuals who participate in and apply for social security and defraud social security benefits or social security fund expenditure into the "blacklist" of social security.

\section{2 analysis of the current situation of the punishment system for doctors and patients' colluding to cheat insurance}

At present our country did not promulgated according to basic health care insurance fraud behavior of special law, punishment more references to insurance fraud behavior "insurance law" relevant provision, for individual basic health care insurance fraud behavior, in Beijing, for example, on the basis of the human social security bureau issued "ginseng protect personnel in violation of the basic medical insurance regulation processing method" of the relevant provisions, in addition to a fine insurance fraud amount 1-3 times, the social security card stop using 3 years, medical treatment charge by individual pay cash in full, a fixed number of year at once.

The social insurance law of the People's Republic of China stipulates that anyone who defrauds social insurance benefits by fraud, falsification of certificates or other means shall be ordered by the social insurance administrative department to return the social insurance benefits he defrauds, and shall be fined for an amount between two and five times the defrauded amount.

Released in 2014, the standing committee of the National People's Congress on the < criminal law of the People's Republic of China > article 266 interpretation announcement regulation, to fraud, fake documents or other means to defraud pension, medical treatment, inductrial injury, unemployment, birth and other social insurance or other social security benefits, belongs to the fraud of public or private property, shall be investigated for criminal responsibility according to law.

Although the National People's Congress as early as in 2014 has been interpreted as crime insurance fraud behavior, and in the criminal law provisions of the sentencing standards, but because of limited cases be shall be investigated for criminal responsibility according to law, the social influence is small, plus a lot of unclear understanding of health care, legal consciousness, part of the doctor-patient collusion insurance fraud behavior is still not been effectively, and even form tacit collusion between doctors in individual regions, single diddle more subsidies through the modification of hospital diagnosis and treatment, at the same time, those people can submit an expense account more medical costs, the surface looks, insurance fraud behavior of improper benefits not many, but from the society as a whole level, The harm is boundless, what cheat protect behavior to harm finally is the integral interest of all ginseng protect person. 


\section{$9^{\text {th }}$ INTERNATIONAL CONFERENCE ON MANAGEMENT , ECONOMICS AND HUMANITIES}

\section{Conclusions and Suggestions}

First, adhering to the concept of "governing the country by law", strengthening the construction of the legal system, and at the same time improving the legal degree of basic medical security management, we will severely crack down on insurance frauds of all parties in basic medical security in accordance with the law. For this reason, it is necessary to issue targeted classification and evaluation standards for the harmfulness of fraudulent insurance ACTS in basic medical security, and form a standardized legal punishment system on this basis, so as to carry out legal and legal control against fraudulent insurance ACTS in basic medical security.

The second is to completely cut off the relationship between the amount of drugs and medical equipment sold by hospitals and doctors and their income, so that hospitals and doctors can return to the role of service providers. Only by making the use and consumption of drugs and medical devices led by hospitals and doctors completely isolated from the income of doctors and hospitals can the excessive medical treatment and even insurance fraud caused by the profit-making impulse of hospitals and doctors be fundamentally prevented.

Third, the coverage, fields and expense standards of basic medical insurance should be further clarified to avoid the abuse, embezzlement and fraud of basic medical insurance. Research has shown that more clear about the domain of medical insurance coverage and system design, more can effectively avoid the occurrence of insurance fraud behavior ${ }^{[9]}$, in the field of clear basic medical coverage and, on the basis of the use of drugs and medical equipment procurement and also make corresponding clear specification, from the institutional effectively avoid the happening of the basic medical insurance fraud.

Fourth, relying on "informatization", strengthen the management of basic medical security through "big data" management and analysis, and put an end to insurance fraud. Improve the informatization degree of each link and process of basic medical security. While collecting and summarizing information, analyze it and discover the abnormal situation. While analyzing the evolution and operation mechanism of basic medical security by means of "big data", the abnormal situations deviating from the general state are locked, so as to precisely locate the occurrence link of insurance fraud and make targeted treatment for it.

Fifth, strengthen the popularization and publicity of the correct use of basic medical security for the public, and reduce the public's impulse to cheat insurance. Only by making the public truly realize that the correct way to use basic medical security is to "prevent gradual decline", can we fundamentally reverse the moral hazard caused by the false belief that the funds in basic medical security are idle funds. Only by making the public realize that basic medical security is a safeguard system directly related to their vital interests, can the initiative of supervision and prosecution of insurance fraud be mobilized, so as to transform the potential perpetrators of insurance fraud into supervisors and maintainers of system operation. 


\section{$9^{\text {th }}$ INTERNATIONAL CONFERENCE ON MANAGEMENT , ECONOMICS AND HUMANITIES}

\section{Reference}

[1] Ma Weishu, Zhang Zaisheng. (2008). Economic analysis of insurance fraud in medical insurance market. Modern Economic Research, vol. (11), pp. 46-49.

[2] Liu Zhiyong, Sun Meng, Wang Xiaoyu. (2016). Sanming “in”the public hospital reform pain point. Chinese Health, vol. (4), pp.107.

[3] Li Yazi, Wang Heping, Ling Daoshan, Li Guolei. (2016). Case study of basic medical insurance fraud: a case study of new rural cooperative medical care in a certain province. China's health economy, vol. 35(04), pp.34-37.

[4] Huang Guan. (2017). A comparative analysis of China and the United States from the perspective of insurance fraud in basic medical security. Social security and welfare, vol. (04), pp. 86-90.

[5] Lou Yu. (2018). On the regulation method of medical service agreement on fraudulent insurance - legal theory and system design of punitive compensation. Observation, vol. (10), pp. 17-20.

[6] Xiong Maoyou. (2016). How to learn sanming medical reform mode. China's fiscal, vol. (2), pp. 64-65.

[7] Sun Shaorong. (2015).Institutional Engineering. Science Press. Beijing.

[8] Guo Wenbo, Zhang Lan, Li yuanfeng, Zheng xiaohua. (2012). Analysis on the effect of total medical insurance cost control payment method. China's health economy, vol. 31, pp. 25-27. 